\title{
Preventative Health Screening Amongst Women Who Have Experienced Intimate Partner Violence
}

\author{
Sandra K. Cesario, Fuqin Liu*, Heidi Gilroy, Anne Koci, Judith McFarlane, John Maddoux
}

\begin{abstract}
Objectives: Partner violence affects one in three women worldwide and is linked to higher rates of women's cancers with increased utilization of health care services. However, evidence of the association between severity of violence and health screening behaviors (i.e., Pap testing, mammography, \& clinical/self-breast exams [SBEs]) is scant. The purpose of this study was to identify engagement of abused women in preventive health screening behaviors.

Materials and Methods: This was a cross-sectional study of 284 abused women with children. Participants were part of a 7-year prospective study to examine the treatment efficacy of the 2 models most often offered to abused women. At the 24th month interview, data on health promotion behaviors were collected via investigator designed instrument. Both descriptive and chi square analysis were used for data analysis.

Results: Abused women were more likely to engage in preventative health behaviors than the general US female population but had a higher incidence of sexually transmitted infections (STIs) and abnormal Pap test results with variance based on race, ethnicity, immigration status, language, and the type of intimate partner violence (IPV) services initiated. Preventative screening was adequate, but there was poor follow-up care for abused women who received abnormal results.

Conclusion: Findings suggest urgent need to maintain high rates of screening and initiate better follow-up care. Recognition of the potential co-existence of gynecological infections or cervical cellular irregularities with the experience of partner abuse may lead health care providers to improved diagnosis and treatment for both IPV and abnormal gender-specific health care outcomes.

Keywords: Preventative health screening, Intimate partner violence (IPV), Cancer screening, Partner abuse
\end{abstract}

\section{Introduction}

Preventative screening is the most effective way of ensuring that cancers are detected at early stages (1). Pap smear, also known as Pap test, is a screening test for cervical cancer. The American Cancer Society (ACS), American Society for Colposcopy and Cervical Pathology (ASCCP), American Society for Clinical Pathology (ASCP), United States Preventive Services Task Force (USPSTF), and the American College of Obstetricians and Gynecologists (ACOG) all recommended in 2012 that Pap testing begin at age 21 and continue every 3 years until the age of 65 . Both mammography and self-breast exam (SBE) are used to screen for breast cancer. There is less agreement on recommendations for mammography with the USPSTF stating that screening begins at age 50 and repeated every two years whereas the ACS suggests that screening begin at age 40 and continue annually. There is general consensus that SBE should begin by age 20 and clinical breast exams should be a part of all well-woman exams.

Other commonly recommended preventative screening tests in well-woman care settings include sexually transmitted infections (STI) testing and HIV testing. Despite the recommendations, many women do not utilize the preventative health screening services. For example, $67 \%$ of US women in the general population reported having a Pap test in the last 12 months and 9\% acknowledged never having a Pap test in year 2010 (2). Preventative health screening among women who experience intimate partner violence (IPV) is more challenging as the perpetrator may restrict her access to preventative healthcare.

Any form of physical, psychological, economic, verbal, or sexual abuse by current and/or former spouses and dating partners can be classified as IPV (1). The global estimates of IPV are as high as 50\% (3). The literature presents conflicting results with regards to preventive health seeking behaviors among abused women. One study found that IPV is independently associated with inadequate Pap tests (4). Cadman et al (5) found that women who have experienced sexual abuse are less likely to have cervical screening. Another study also found that the odds of receiving Pap tests, and STI/HIV testing increase for women who saw an obstetrician-gynecologist independent of IPV (6). On the other hand, studies reported that abused women have higher healthcare utilization and costs compared to non-abused women (7-9). Brown et al (10) found that HIV testing and self-breast examination rates are higher 
among abused women compared with women without an IPV history.

Despite the higher rates of overall healthcare use and healthcare costs, preventive healthcare utilization among IPV-exposed women is comparably low (6). Women who reported safety concerns reported less cancer testing, fewer clinical breast examinations, and mammography compared to women who did not report safety concerns (11). Furthermore, women's preventive health seeking behavior is affected by their awareness regarding abuse and willingness to disclose the abuse (12). Women with a history of IPV may be more vigilant about certain screening practices related to their health. This could explain some of the conflicting results regarding the preventive screening practices of abused women when compared with nonabused women. Nonetheless, preventive health screening is an important health issue among abused women because a growing body of research suggests a positive association between cancers and IPV (13-15). Additionally, IPV is also associated with STIs (16-18), and a higher risk of HIV $(19,20)$.

Clearly, partner violence is linked to higher rates of women's cancers and increased use of health care services. However, evidence of the association between severity of violence and preventative health screening behaviors (i.e., Pap testing, mammography, \& clinical/SBEs) is lacking. The purpose of this study was to identify engagement of abused women in preventive health screening behaviors and to determine if screening is occurring at optimal rates as recommended by US guidelines.

\section{Methods}

Participants were 284 abused women with children who reached out to safe shelter or the justice system for assistance. The women ranged in age from 18 to 52 (median age 30 years), 79\% of Hispanic origin, 37\% having immigrant status, and the majority living at poverty levels as determined by the U.S. Department of Health and Human Services guidelines (21). This report is part of a 7-year prospective study to examine the treatment efficacy of safe shelter and justice services. The women are interviewed every 4 months for 7 years to assess the impact of abuse on safety, health, and functioning. Details of the 7-year study are reported elsewhere (22). The self-reported data presented herein were obtained by interview at the 24th month of the study to explore relationships between key demographics (i.e., immigrant status, ethnicity, primary language, and intervention group, and select recommended preventative health care behaviors). Preventive health measures chosen for this study were based on US national guidelines for women and included breast self-examination, pap smears, and sexually transmitted diseases. The questionnaire is presented in Table 1.

\section{Data Analysis}

Frequencies were tabulated on questionnaire responses. In order to test for differences in preventative health promotion behaviors, a series of crosstabulations with
Table 1. Health Promotion Questions asked of Study Participants

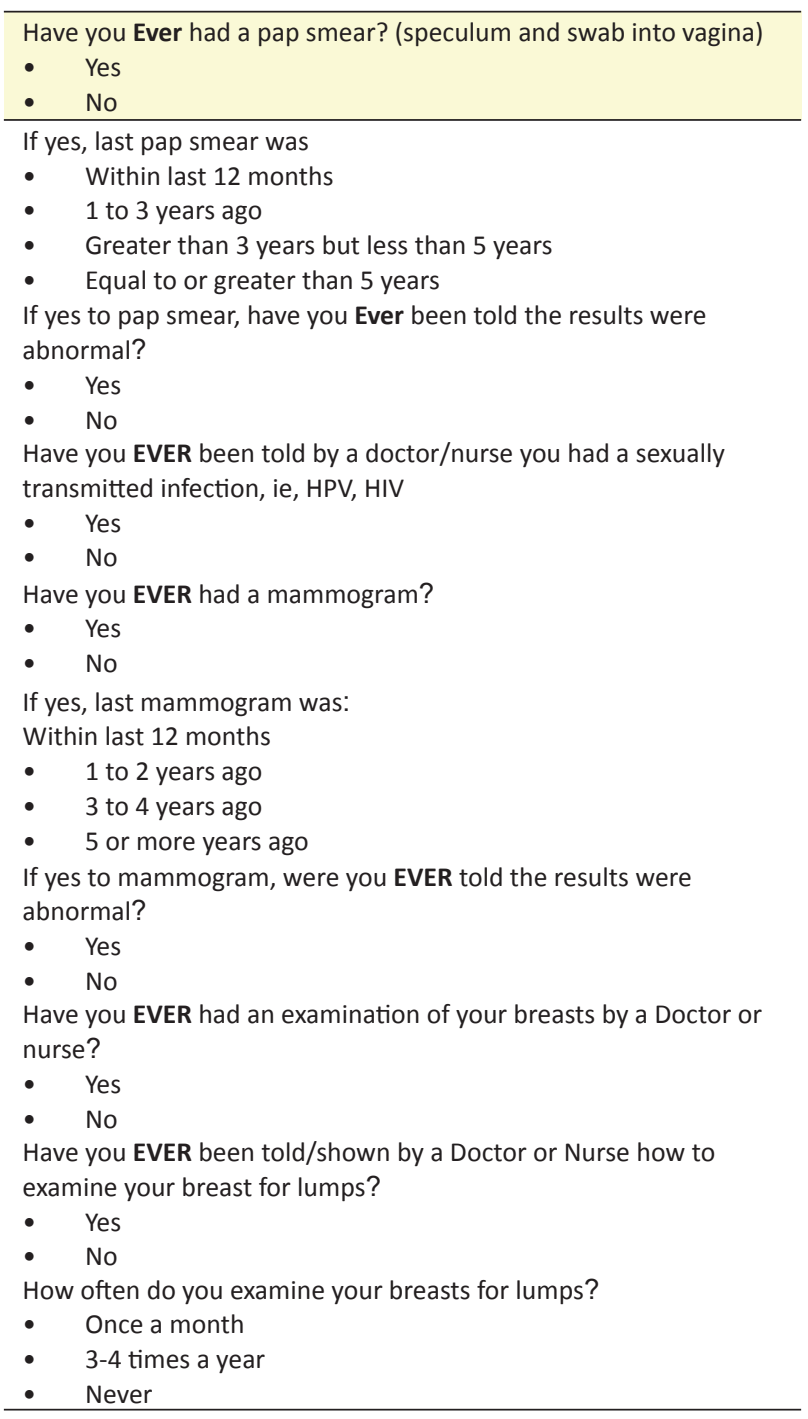

Pearson's chi-square were conducted by key demographic variables (i.e., language spoken, immigrant status, ethnicity, group). Cramer's V is used as a measure of effect size with chi square analysis. Values of 0.25 or high indicate a very strong relationship; 0.15 to 0.25 a strong relationship; 0.11 to 0.15 a moderate relationship, 0.06 to 0.10 a weak relationship, and 0.01 to 0.05 no or negligible relationship.

\section{Results}

The 284 abused women participating in this study were more likely to have had a Pap test, mammogram, and engage in SBE than the general population of women in the Unites States. A summary of the results may be found in Table 2.

In regard to breast health, just over two thirds of the sample reported receiving a mammogram (66.5\%), and of those women $40 \%$ reported having had a mammogram within the past 12 months. Furthermore, $90.8 \%$ of the women reported receiving a breast exam by a healthcare provider, and $44.2 \%$ reported doing breast self-examination on a monthly basis. There was also a significant relationship and moderate effect size between language spo- 
Table 2. Frequencies and percentages of mother health items

\begin{tabular}{|c|c|c|}
\hline & Number & $\%$ \\
\hline \multicolumn{3}{|l|}{ Ever had pap smear } \\
\hline No & 1 & 0.3 \\
\hline Yes & 283 & 99.6 \\
\hline \multicolumn{3}{|l|}{ Last pap smear } \\
\hline Within 12 months & 182 & 60.3 \\
\hline 1 to 3 years & 62 & 21.9 \\
\hline 3 to 5 years & 13 & 4.6 \\
\hline More than 5 years & 26 & 9.2 \\
\hline \multicolumn{3}{|l|}{ Ever had abnormal pap } \\
\hline No & 200 & 70.7 \\
\hline Yes & 83 & 29.3 \\
\hline \multicolumn{3}{|l|}{ Ever had STI } \\
\hline No & 202 & 71.1 \\
\hline Yes & 82 & 28.9 \\
\hline \multicolumn{3}{|l|}{ Ever had mammogram } \\
\hline No & 189 & 66.5 \\
\hline Yes & 95 & 33.5 \\
\hline \multicolumn{3}{|l|}{ Last mammogram } \\
\hline Within 12 months & 38 & 40.0 \\
\hline 1 to 3 years & 22 & 23.2 \\
\hline 3 to 4 years & 14 & 14.7 \\
\hline 5 or more years & 21 & 22.1 \\
\hline \multicolumn{3}{|c|}{ Ever had abnormal mammogram } \\
\hline No & 78 & 83.0 \\
\hline Yes & 16 & 17.0 \\
\hline \multicolumn{3}{|l|}{ Ever had breast exam } \\
\hline No & 26 & 9.2 \\
\hline Yes & 258 & 90.8 \\
\hline \multicolumn{3}{|c|}{ Ever shown how to self-exam breast } \\
\hline No & 41 & 14.4 \\
\hline Yes & 243 & 85.6 \\
\hline \multicolumn{3}{|c|}{ Frequency of breast self-exam } \\
\hline Once a month & 117 & 44.2 \\
\hline 3 to 4 times per year & 75 & 28.3 \\
\hline Never & 73 & 27.5 \\
\hline
\end{tabular}

Note. Percentages shown are valid percentages

ken and having been shown how to give oneself a breast exam, $\chi^{2}(1)=6.09, P=.014$, Cramer's $V=0.147$. A greater proportion of women who spoke English $(n=181,88.7 \%)$ reported that they had been shown how to give themselves a breast exam compared to women who speak Spanish ( $\mathrm{n}=61,77.2 \%)$.

Nearly all the women in the sample (99.6\%) reported having a Pap smear in their lifetimes and $60.3 \%$ reported having this test within the past 12 months. The variance in the length of time that has passed since the last Pap test varied by race, ethnicity, and immigration status. There was a significant relationship and strong effect size between ethnicity and time of last Pap smear, $\chi^{2}(9)=17.63, P=$ .040 , Cramer's $V=0.250$. A greater proportion of Black participants $(n=56,78.9 \%)$ reported having had a pap smear in the past year compared to White women $(\mathrm{n}=$ $34,54.8 \%)$. There was also a significant relationship and strong effect size between immigrant status and date of last pap smear, $\chi^{2}(3)=8.99, P=.029$, Cramer's $V=0.179$. A greater proportion of women born in the United States $(\mathrm{n}=125,69.4 \%)$ reported having had a pap smear in the past year compared to women born outside of the United States $(n=56,54.9 \%)$.

A more alarming finding was that greater than two-thirds of the women in the study $(70.7 \%)$ reported receiving abnormal Pap test results. There was also a significant relationship between ethnicity and having had an abnormal pap smear, $\chi^{2}(3)=17.27, P<.001$, Cramer's V $=0.247$. There was a greater proportion of White women $(n=31$, $50.0 \%$ ) who had irregular pap smears compared to both Black $(\mathrm{n}=17,23.9 \%)$ and Hispanic $(\mathrm{n}=31,23.7 \%)$ women. There was a significant relationship between immigrant status and having had an irregular pap smear, $\chi^{2}(1)$ $=8.46, P=.004$, Cramer's $V=0.173$. A greater proportion of women who were born in the United States $(n=63$, $35 \%$ ) reported having had an abnormal pap smear compared to those born outside of the United States ( $n=19$, $18.6 \%)$.

Women in the study reported a higher incidence of STIs which could account for the increased frequency of abnormal Pap test results. There was a significant relationship and strong effect size between immigrant status and having had an STI, $\chi^{2}(1)=15.67, P<.001$, Cramer's V = 0.235 . A greater proportion of women born in the United States $(n=66,36.7 \%)$ reported having had an STI compared to women born outside of the United States ( $n=15$, $14.6 \%)$.

\section{Discussion}

In recent years there has been a shift in and stronger emphasis placed on health promoting behaviors in the United States. The behaviors which tend to receive the most attention are often associated with diet and lifestyle changes related to the prevention of obesity and cardiovascular disease. This study, however, shifts the focus to utilization of preventative screening by women who have experienced IPV. The finding that women in this study were more likely to have had a Pap test, mammogram, or engage in SBE when compared to non-abused US women is consistent with the findings of Brown et al (10). This is in stark contrast to the work of Black et al (23) and Loxton et al (4) who found that IPV was independently and strongly correlated with no recent preventative gynecologic care and inadequate PAP testing even after accounting for commonly-cited barriers to accessing care such as lack of education, lack of transportation, poverty, and depression. The difference in findings between these studies and the current study may relate to the age of the participants. Older abused women (over the age of 40) have been cited to be late in their routine Pap smear testing (24). The median age of the women in our study is 30 years. While previous researchers (25) suggest that women who have experienced IPV tend to exhibit gynecological care avoidance behaviors associated with the sexual violation, the women in the current study did not express this concern. Higher incidence of STIs and abnormal Pap test results found in this study is likely not related to the fact that many of the women are living under the US Federal poverty line. Other factors, such as age, marital status, and sexual his- 
tory, are more reliable predictors for HPV (26). Adimora and Schoenback (27), however, assert that poverty may affect the other risk factors for STI's, including HPV. For example, decreased marriage stability in poor communities may increase the number of sexual partners a person may have. Poverty does place women with cervical dysplasia at higher risk for cervical cancer because it often results in delayed or absent screening and treatment (28).

Though the incidence of and mortality from cervical cancer has been declining in the United States for several years, women with a history of partner violence have an increased prevalence of invasive cervical cancer (13). In this study of abused women, a greater proportion of women who were born in the United States reported being screened for cervical cancer (69.4\%) compared to those born outside of the United States (54.9\%). These results are modest compared to Tsui and associates (29) who found foreign born women three times more likely not to receive cervical cancer screening than US born women. Without proper screening, women are at higher risk for invasive cervical cancer. Of the women screened in our study, a greater proportion of women who were born in the United States reported having had an abnormal pap smear compared to those born outside of the United States. Though comparison studies are lacking in the research, we do know the incidence of cervical cancer in the United States from $2006-2010$ is $7.7 \%$ for Whites, $10.3 \%$ for Blacks, and $10.9 \%$ for Hispanics (30) which may suggest that those born outside of the United States would report more abnormal Pap smears.

Black participants in the current study reported having had a Pap smear in the past year more often than White study participants. This is consistent with the findings reported by Ashok and colleagues (31) who reported black women were least often tested for a Pap smear $>3$ years ago among their study populations, indicating that more factors other than ethnicity should be considered to understand Pap smear testing behavior. Because the black women in our study were victims of IPV who reached out to safe shelter or the justice system for assistance for the first time, the higher rates of Pap smear test may be related to women's other help-seeking behaviors.

Women who experience symptoms of STIs are more likely to seek treatment and a higher incidence of STI's can lead to abnormal Pap test results. A greater proportion of White women had irregular pap smears compared to both Black and Hispanic women which may be related to greater healthcare use by White women and associated screening (29). Data were not collected from the women in the study regarding the specific type of STI or if the Pap testing was done concurrently with HPV screening. Abnormal Pap results with concurrent positive HPV screen suggest a greater risk for developing cervical cancer.

A greater proportion of women who spoke English ( $\mathrm{n}=$ $181,88.7 \%$ ) reported that they had been shown how to give themselves a breast exam compared to women who speak Spanish which is explained by more acculturation and use of healthcare by English speakers. This may be influenced by the lack of Spanish-speaking providers in some health care settings in the United States.

\section{Implications}

In its 2013 Clinical and Policy Guidelines, the World Health Organization (WHO) (3) recommended screening for IPV when assessing for conditions that may be affected by violence. This research reinforces previous research that indicates that abused women are more likely to experience STI's and abnormal Pap smears. This is an indication that women seeking gynecological services, such as Pap smears, should also be screened for IPV. IPV screening is now covered by US policy in the Affordable Care Act (ACA) and is available to insured women free of charge (32).

At this time, there are no specific guidelines on screening (33), but a recent systemic review for the USPSTF recommendations has identified five screening instruments as having high diagnostic accuracy. The list includes the Spanish and English versions of the 4-item Hurt, Insult, Threaten Scream instrument and the Ongoing Violence Assessment Tool (34). Once screening has occurred and IPV has been identified, the HHS Office of Women's Health (33) offers suggestions that all providers can provide brief counseling. The provider should first promote safety, discuss the connection of any medical issues with IPV, and connect the woman to appropriate resources. The HHS Family Violence Prevention and Services Program website has information about IPV with links to national and state resources (http://www.acf.hhs.gov/programs/ fysb/programs/family-violence-prevention-services).

\section{Conclusion}

While there is abundant evidence that the prevalence of IPV impacts health and health care utilization, little is known about its linkages to cancer prevention and screening, especially in the immigrant population. The higher incidence of STIs and abnormal cervical screens warrants continued vigilance and promotion of regular health care screening for abused women. In addition to Pap testing and testing for STIs, it is recommended that HPV testing also be done as well as bimanual pelvic exams as indicated. Counseling for consideration of administering the HPV vaccine to the children of women living in unsafe situations could also be suggested.

More effort is needed to promote acceptance of the latest evidence-based recommendations so that all women receive the maximal benefits of cervical cancer screening and other well-woman care. These findings indicate the urgency to maintain high rates of screening and emphasize the need for follow-up care to address the frequently occurring abnormal findings. Recognition of the potential co-existence of gynecological infections or cervical cellular irregularities with the experience of partner abuse may lead to improved gender-specific health outcomes.

\section{Ethical issues}

The Institutional Review Board reviewed and approved 
the study prior to participant recruitment and data collection.

\section{Financial support}

This study was funded by a substantial grant from The Houston Endowment, USA.

\section{Conflicts of interest}

The authors have no conflicts of interest to disclose.

\section{Acknowledgements}

We appreciate the unflagging assistance and support of the administrators and staff of the five shelters in Harris County and the Chief and staff of The Harris County District Attorney's Office, Family Criminal Law Division.

\section{References}

1. Centers for Disease Control and Prevention. Cancer Screening - United States, 2010. MMWR. 2012;61(3):41-45. Available from

2. Frost JJ. Women's use of sexualand reproductive health services: Trends, sources of careand factors associated with use, 1995-2010. New York: Guttmacher Institute; 2013. http://www.guttmacher.org/pubs/sources-ofcare-2013.pdf

3. World Health Organization. Policy and Clinical Practice Guidelines for Responding to Intimate Partner Violence and Sexual Violence. Geneva: WHO; 2013.

4. Loxton D, Powers J, Schofield M, Hussain R, Hosking $\mathrm{S}$. Inadequate cervical cancer screening among mid-aged Australian women who have experienced partner violence. Prev Med. 2009;48(2):184-188. doi: 10.1016/j.ypmed.2008.10.019.

5. Cadman L, Waller J, Ashdown-Barr L, Szarewski A. Barriers to cervical screening in women who have experienced sexual abuse: an exploratory study. J Fam Plann Reprod Health Care. 2012;38(4):214-220. doi: 10.1136/jfprhc-2012-100378.

6. McCall-Hosenfield J, Chuang C, Weisman C. Prospective association of intimate partner violence with receipt of clinical preventive services in women of reproductive age. Womens Health Issues. 2013;23(2):e109-e116. doi: 10.1016/j. whi.2012.12.006.

7. Rivara FP, Anderson ML, Fishman P, et al. Healthcare utilization and costs for women with a history of intimate partner violence. Am J Prev Med 2007;32(2):89-96. doi: 10.1016/j.amepre.2006.10.001.

8. Ulrich YC, Cain KC, Sugg NK, Rivara FP, Rubanowice DM, Thompson RS. Medical care utilization patterns in women with diagnosed domestic violence. Am J Prev Med. 2003;24(1):9-15.

9. Coker AL, Reeder CE, Fadden MK, Smith PH. Physical partner violence and Medicaid utilization and expenditures. Public Health Rep. 2004;119(6):557567.

10. Brown MJ, Weitzen S, Lapane KL. Association between intimate partner

11. violence and preventive screening among women. J Womens Health 2013;22(11):947-952. doi: 10.1089/ jwh.2012.4222

12. Cronholm P, Bowman M. Women with safety concerns report fewer gender-specific preventive healthcare services. J Womens Health. 2009;18(7):1011-1018. doi: 10.1089/jwh.2008.0968.

13. Roelens K, Verstraelen H, Egmond KV, Temmerman M. Disclosure and health-seeking behavior following intimate partner violence before and during pregnancy in Flanders, Belgium: A survey surveillance study. Eur J Obstet Gynecol Reprod Biol. 2008;137(1): 37-42.

14. Coker AL, Hopenhayn C, DeSimone CP, Bush HM, Crofford L. Violence against women raises risk of cervical cancer. J Womens Health. 2009;18(8):11791185. doi: 10.1089/jwh.2008.1048.

15. Wise LA, Palmer JR, Boggs DA, Adams-Campbell LL, Rosenberg L. Abuse victimization and risk of breast cancer in Black Women's Health Study [corrected]. Cancer Causes Control. 2011;22:659-669. doi: 10.1007/s10552-011-9738-3.

16. Cesario S. Linking cancer and intimate partner violence: The importance of screening women in the oncology setting. Clin J Oncol Nurs. 2014;18(1):6573. doi: 10.1188/14.CJON.65-73.

17. Campbell JC. Health consequences of intimate partner violence. Lancet. 2002;359:1331-1336.

18. Dillon G, Hussain R, Loxton D, Rahman S. Mental and physical health and intimate partner violence against women: A review of the literature. Int J Family Med. 2013;2013:313909. doi: 10.1155/2013/313909.

19. Vos T, Astbury J, Piers LS, et al. Measuring the impact of intimate partner violence on the health of women in Victoria, Australia. Bull World Health Organ. 2006;84(9):739-744.

20. Mathew A, Smith L, Marsh B, Houry D. Relationship of intimate partner violence to health status, chronic disease, and screening behaviors. J Interpers Violence. 2013;28(12):2581-2592. doi: 10.1177/0886260513497312.

21. Miner S, Ferrer L, Cianelli R, Bernales M, Cabiese B. Intimate partner violence and HIV risk behaviors among socially disadvantaged Chilean women. Violence Against Women. 2011;17(4):517-531. doi: $10.1177 / 1077801211404189$.

22. U.S. Department of Health and Human Services. HHS Poverty Guidelines. http://aspe.hhs.gov/ poverty/12poverty.shtml. Accessed January 2014.

23. McFarlane J, Nava A, Gilroy H, Paulson R, Maddoux J. Testing two global models to prevent violence against women and children: methods and baseline data analysis of a seven-year prospective study. Issues Ment Health Nurs. 2012;33(12):871-881. doi: 10.3109/01612840.2012.731135.

24. Black M, Basile K, Breiding M, et al. The National Intimate Partner and Sexual Violence Survey 
(NISVS): 2010 Summary Report. Atlanta, GA: National Center for Injury Prevention and Control, Centers for Disease Control and Prevention; 2011.

25. Gandhi S, Rovi S, Vega M, Johnson M, Ferrante $\mathrm{J}$, Chen $\mathrm{PH}$. Intimate partner violence and cancer screening among urban minority women. J Am Board Fam Med. 2010;23(3):343-353. doi: 10.3122/ jabfm.2010.03.090124.

26. Ackerson K. A history of interpersonal trauma and the gynecological exam. Qual Health Res. 2012;22(5):679-688. doi: 10.1177/1049732311424730.

27. Dunne EF, Unger ER, Sternberg M, et al. Prevalence of HPV infection among females in the United States. JAMA. 2007;297(8):813-819.

28. Adimora AA, Schoenbach VJ. Social context, sexual networks, and racial disparities in rates of sexually transmitted infections. J Infect Dis. 2005;191(suppl 1):S115-S122.

29. Downs LS, Smith JS, Scarinci I, Flowers L, Parham G. The disparity of cervical cancer in diverse populations. Gynecol Oncol. 2008;109(2 suppl):S22-S30. doi: 10.1016/j.ygyno.2008.01.003.

30. Tsui J, Saraiya M, Thompson T, Dey A, Richardson L. Cervical Cancer Screening among Foreign-Born Women by Birthplace and Duration in the United States. J Womens Health 2007;16(10):1447-1457. doi:10.1089/jwh.2006.0279.
31. U.S. Cancer Statistics Working Group. United States Cancer Statistics: 1999-2010 Incidence and Mortality Web-based Report. Atlanta: U.S. Department of Health and Human Services, Centers for Disease Control and Prevention and National Cancer Institute; 2013.

32. Ashok M, Berkowitz Z, Hawkins NA, Tangka F, Saraiya M. Recency of Pap testing and future testing plans among women aged 18-64: Analysis of the 2007 Health Information National Trends Survey. J Womens Health. 2012;21(7):705-712. doi: 10.1089/ jwh.2012.3562.

33. James L, Schaeffer S. Interpersonal and Domestic Violence Screening and Counselling: Understanding New Federal Rules and Providing Resources for Health Providers. San Francisco, CA: Futures Without Violence; 2012.

34. Office of Women's Health. Health Care Providers and Screening and Counseling for Interpersonal and Domestic Violence. http://www.womenshealth.gov/ publications/our-publications/fact-sheet/screeningcounseling-fact-sheet.html\#c. Accessed 2014 January.

35. Nelson HD, Bougatsos C, Blazina I. Screening women for intimate partner violence: a systematic review to update the US Preventive Services Task Force recommendation. Ann Intern Med. 2012;156(11):796-808.

Copyright $(2015$ The Author(s); This is an open-access article distributed under the terms of the Creative Commons Attribution License (http://creativecommons.org/licenses/by/4.0), which permits unrestricted use, distribution, and reproduction in any medium, provided the original work is properly cited. 